\title{
Effects of Influential Factors on Entrepreneurial Intention of Postgraduate Students in Malaysia \\ $1^{*}$ Omid Yaghmaei and ${ }^{2}$ Iman Ghasemi
}

\author{
${ }^{1}$ International Business School, Universiti Teknologi Malaysia (UTM), International Campus, \\ Kuala Lumpur, Malaysia \\ ${ }^{2}$ Faculty of Management, Universiti Teknologi Malaysia (UTM), International Campus, \\ Kuala Lumpur, Malaysia
}

*Correspondence: Omid Yaghmaei (email: oyaghmaei@gmail.com) Keywords: Entrepreneurial Intention; Entrepreneurship; Previous Experience; Perceived
Behavioral Control; Subjective Norms

\begin{abstract}
Entrepreneurship leads to massive economic benefits, such as economic growth, reduction in unemployment, and development of economies. Understanding the factors that impact on entrepreneurial intention is the primary and critical step towards predicting and developing entrepreneurial activities. Due to economic and social developments, entrepreneurial intention is gaining more importance in developing countries like Malaysia. The aim of this study is twofold; first, to find out the relationship between respondents' attitude, subjective norms, perceived behavioral control, education, previous experience and age with intention to own a business; and second, to examine what particular factors are more influential on entrepreneurial intentions of postgraduate students in Malaysia. The study was carried out with master students. Data was collected from 380 male and female master students in Universiti Teknologi Malaysia (UTM) who were in their final year of study and were considered appropriate for a decision in entrepreneurship. The analysis of the results showed that, firstly, attitude has direct effect on entrepreneurial intention but age has inverse effect. Secondly, it was concluded that these two variables were more important than others in modeling and predicting entrepreneurial intention among postgraduate students in Malaysia.
\end{abstract}

\section{INTRODUCTION}

A great number of studies have shown that entrepreneurship has lead to massive economic benefits, such as economic growth, reduction in unemployment, and development of economies. As a result, various developing and developed countries have focused on entrepreneurship studies, and how to create and improve entrepreneurial skills. Entrepreneurial intention has become a strategy against unemployment, and a significant tool towards development (Bygrave, 1993). Nevertheless, since the beginning of these attempts, dramatic gaps have existed in terms of what factors create an entrepreneur. In other words, which individuals would like to become an entrepreneur?

Understanding the factors that influence entrepreneurial intention is the primary and critical step towards predicting and developing entrepreneurial activities. Studies show various, and yet contradict views towards this matter. While some researchers link personal traits and characteristics to entrepreneurial intention, others look at external factors such as exposure to entrepreneurial activities. Despite the existence of numerous studies on entrepreneurial intention, there is a questionable issue in determining the factors that lead to higher or lower entrepreneurial intention. Moreover, there is no unanimous approach that allows predicting entrepreneurship. In fact, some studies argue that none of the proposed factors can truly predict who will become an entrepreneur. Gartner et al. (2000) in their study claimed that neither personality traits, nor background factors are reliable predictors of entrepreneurship likelihood of an individual. The present study aims to investigate the influential factors on entrepreneurial intentions of postgraduate students in Malaysia. 


\section{INFLUENTIAL FACTORS ON ENTREPRENEURIAL INTENTION}

\subsection{Education}

A great number of research studies have been conducted regarding the impact of education on entrepreneurship. Despite the existence of the studies, the concepts of education and entrepreneurial intention require further investigation (Peterman \& Kennedy, 2003). The main reason behind this lack of knowledge is the complex, yet contradictory results of the previous studies. For instance, findings on the impact of formal education on entrepreneurial intention are discrepant. While some researchers claim that formal education reduces the intention to become entrepreneurs, others have obtained opposite results.

The next point is that most of the previously conducted researches have concentrated on the direct influence of education on entrepreneurial intention, while only a few have looked at the impact of education as a mediator on entrepreneurial intention. Some studies have shown that education does not significantly impact on the likelihood of turning into an entrepreneur, whereas in case of higher levels of education, the impact becomes more significant (Goedhuys \& Sleuwaegen, 2000).

On the contrary, some studies have shown that the impact of education on entrepreneurial intention is not linear. Some researchers concluded that higher education has positive impact on entrepreneurial intention. It was particularly found that business courses lead to higher intention levels to become an entrepreneur. There is also a positive link between higher education and further success in opening a business. Another study done in the U.S. showed that there is positive relationship between the number of years of education, and intention to become an entrepreneur.

On the contrary, some studies have indicated that higher level of education has a negative impact on the entrepreneurial intention. In fact, these studies showed that those with diploma and undergraduate degrees show higher likelihood of becoming an entrepreneur (Kirchhoff \& Greene, 1995). These studies suggest that the reason behind such findings is that usually people with higher levels of education tend to have job opportunities so that they are less likely to start their own business. Moreover, some researches indicate that higher level of education leads to lower curiosity and risk taking (Naughton, 1987). Even some research studies refer to the type of the education, and the system through which it is proposed. For instance, it has been shown that traditional education leads to lower creativity, curiosity, and risk taking, which later leads to lower tendency to become an entrepreneur (Ronstadt, 1989). Another study argues that traditional business courses tend to create analytical personality, and reduce the risk taking of the students, which scares them from taking the risk of becoming an entrepreneur. In line with these findings, Shapero and Sokol (1982) raise the issue of efficient business course, as they usually lead to create the thinking that small businesses are not worth it, and lead to failure.

Peterman and Kennedy (2003) claimed that formal education reduces the chances of becoming entrepreneurs, as these types of education are usually designed to prepare students to work in corporations. Kilby (1971) concluded that universities and business schools can develop entrepreneurs only after a radical change in their intellectual and educational priorities.

\subsection{Age}

Age is generally associated with entrepreneurship. While some researchers posit that entrepreneurship is a game for the young people, others argue that it rises with age, and the association is inconclusive. Research studies have shown that age can have an impact on entrepreneurship. It has been claimed that older individuals have less tendency to start a venture compared to the younger ones (Levesque \& Minniti, 2006). In agreement with this finding, Reynolds (1987) also indicated that those who are younger tend more to become an entrepreneur. However, the results of some other studies are contradictory. For instance, it has been found that older individuals show more tendency to become an entrepreneur.

From the association of risk taking, innovation, energy, and motivation with business creation, it can also be deduced that entrepreneurship is a game for the young people so that governments target young people for entrepreneurial activities. Levesque and Minniti (2006), 
however, observed that there are insufficient studies on the relationship between age and entrepreneurship and that there is more need for research in this area. An interesting phenomenon is the increasing business creation among retirees and older people. Singh and DeNoble (2003) stated that many people leave their jobs before retirement; however, they tend to later come back and be employed again in bridge-employment, before completing the retirement. According to Singh and DeNoble (2003), such people are suited to go into entrepreneurship due to their experience, savings, and social networks; therefore, they can be regarded as the next generation of entrepreneurs.

\subsection{Role Models}

Role modeling happens when an individual adopts another person's behavior which is accepted as ideal instead of learning it through personal experience (Scherer et al., 1989). The notion that entrepreneurship can be learned from others is based on Bandura Social Learning Theory (1986). This role modeling can happen in professional career of individuals as well. In such case, a person can pursue a certain type of career based on other people's success, in which success being defined as to what extent the model draws satisfaction from the task (Scherer, et al., 1989).

Some studies have shown that there is a significant relationship between having an entrepreneur role model and becoming an entrepreneur. According to Matthews and Moser (1996), apart from the overrepresentation of males, the most consistent result in entrepreneurship research is a correlation with role models. Davidsson (1995) also suggested that lack of role models is one reason for the low number of women entrepreneurs in the society. One special case of role modeling is parental influence. Davidsson (1995) also stated that those children with entrepreneur parents show higher tendency to become an entrepreneur themselves.

Role models are gender specific; sons are more likely to learn from their fathers, while daughters are more likely to learn from their mothers. The role of parents as social role models leads to higher impact of their career choice on their children. Entrepreneur parents usually show higher support of their children to become an entrepreneur as well. However, the influence of role models does not command universal support. Brockhaus and Horwitz (1986) concluded that many entrepreneurs have entrepreneur parents, but entrepreneurs' children do not disproportionately become entrepreneurs themselves. Scherer, et al. (1989) observed that some children of entrepreneurs do not go into entrepreneurship, while individuals without parental role models develop an interest in an entrepreneurial career. However, Krueger (1993) stated that there is no significant relationship between having entrepreneur parents and becoming an entrepreneur. Empirical support is also lacking due to weak testable basis on how this influence takes place and the effect of role models is not well understood (Gupta, et al., 2009).

\subsection{Previous Experience}

Researchers believe that people with prior experience are more likely to start business and more likely to succeed in the business. Prior experience is therefore associated with entrepreneurship. Davidsson (1995) concluded that there is an overrepresentation of people with prior experience among business owners.

It has been shown that those who take the risk of starting their first business show higher tendency to go for the second one as well. This experience can be obtained from a paid job as well. For instance, it has been stated that those who gain experience at their previous job, tend to use their knowledge into more successful entrepreneurship activities. Prior experience is also associated with entrepreneurship as a source of business ideas. Scott and Twomey (1988) found that $30 \%$ of students with work experience said they had a business idea, as opposed to less than $10 \%$ of those who had never worked. Shapero and Sokol (1982) also observed that entrepreneurs who have failed are more likely to succeed. Moreover, those with higher experience are more successful. According to Vesper (1980), those starting their first company tend to be more successful in their second or third attempt. Brockhaus and Nord (1979) stated that personal experience and knowledge can impact the choice of an entrepreneur. However, it has been argued that this influence is not from the prior experience, but from the interpretation and reaction. In general, Robinson et al. (1991) believed that the influence of prior experience on entrepreneurship is unclear. 


\section{Methodology}

\subsection{Research Design}

Attitude, perceived behavioral control, subjective norms, previous experience, education and age have been posited to influence entrepreneurial intention - one's planned to start or own a business (Davidsson, 1995; Shapero \& Sokol, 1982). The aim of this study was, therefore, to generate and expand knowledge about entrepreneurial intention of postgraduate students in Malaysia. To achieve the aim, this correlation study was performed. Correlation describes, in quantitative terms, the degree to which two or more terms are related (Kasomo, 2006). This study examined the relationship among respondents' attitude, subjective norms, perceived behavioral control, education, experience and age with intention to own a business. Figure 1 shows the research framework for this study.

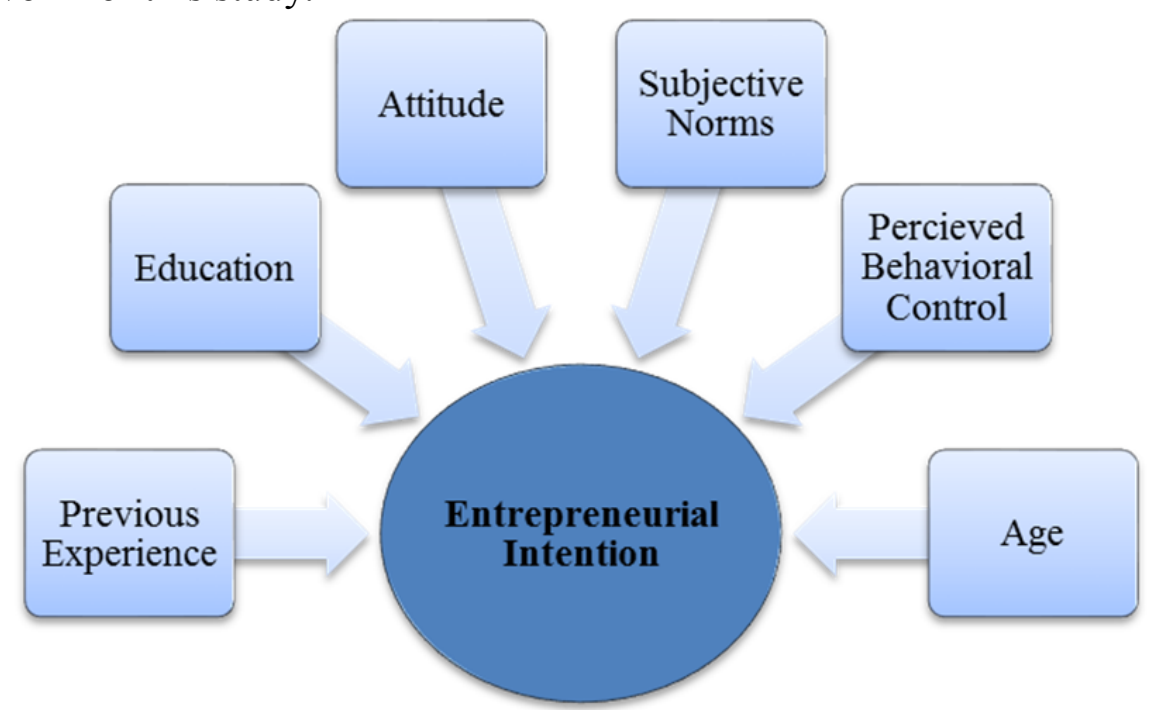

Figure 1: Research Framework

\subsection{Participants}

The study was carried out with master students. Data was collected from 380 male and female master students in Universiti Teknologi Malaysia (UTM) who were in their final year of study and were considered appropriate for a decision in entrepreneurship. Students in their final year were considered appropriate for a decision in entrepreneurship because according to Shapero and Oskol (1982), entrepreneurship is often preceded by a displacement or precipitating event that triggers action. Therefore, in total, 380 students in their final year of study were surveyed.

The sample size of 380 was suitable. Gay and Diehl (1992) indicated that in correlation research, at least 30 participants are required to establish a relationship. Krejcie and Morgan (1970) also observed that, as the population increases, the sample size increases at a diminishing rate and remains eventually constant at slightly more than 380 cases. Therefore, based on Krejcie and Morgan (1970), a sample size not lower than 380 respondents is acceptable. The size of the standard error also largely depends on, and varies inversely with the sample size, and a large sample reduces the standard error and enhances the viability of the study (Kothari, 2004). Kniveton (2004) observed that task of choosing career is not static but part of a developmental process, and that from early fantasy, through tentative stage in the early years of teenage, individuals shift to the realistic stage to focus an appraisal by late adolescence, and adolescence is a time that entrepreneurial aspirations take place, and that these inspirations are stable. It can therefore be expected that the respondents in this study are aware of their career aspirations and that these intentions can predict entrepreneurship.

\subsection{Instrument}

This study was designed to examine the relationship among the attitude, subjective norms, perceived behavioral control, previous education, education, and age with respondent's entrepreneurial intention among postgraduate students in Malaysia. The data were collected using questionnaires completed by the respondents at UTM Kuala Lumpur campus and UTM JB campus 
by online Questionnaire. Participating students were selected, using a combination of stratified random and purposive sampling, from different faculties in UTM.

\subsection{Data Collection Procedures}

The completed questionnaires were all given unique identifiers ranging from 1-380, for ease of reference, and to safeguard data integrity. The different responses were then coded. The nominal gender variable, male, was coded (1) and female (2). Inapplicable questions, such as whether the experience was positive/negative where the respondent had indicated that he/she had never started business, were coded (9) and missing responses (99). The responses to the Likert-scale questions were coded from 1 to 5 for 'strongly disagree' to 'strongly agree'. A database was then created for all the variables, in SPSS, showing what kind of variable the response was: numerical or nominal, the size of the variable, and what the codes meant. The data were then keyed into the database. Thereafter, an exploratory data analysis was run to check for the obvious errors. Necessary corrections were made.

\subsection{Data Analysis}

The data analysis included simple descriptive statistics, correlation, t-test, linear regression analysis, and factor and effect size analysis. While t-test compared means, whether the scores for male and female are different, regression showed relationship between the variables, whether the score related to gender, for predicting future values (Kothari, 2004). Simple descriptive statistics including frequencies and percentages were used to analyze the respondents' background and demographic data. Mean scores and standard deviation were calculated for the Likert-scale questions to develop a participant profile. Correlation analysis was performed to establish the strength of the relationships between respondents' perceptions of personal desirability, social desirability, and feasibility of entrepreneurship with entrepreneurial intention. Subsequent to the correlation analysis, ANOVA was used. Linear regression analysis was also used to determine the predictors of entrepreneurial intention among postgraduate university students. The factor analysis and effect size analysis were also run to determine the factors with the largest influence.

\section{RESULTS AND DISCUSSION}

\subsection{Multiple Regression Analysis}

A multiple regression analysis was used to study the relationship between previous experience, education, attitude, subjective norms, behavioral control and age as independent variables and entrepreneurial intention as dependent variable. The main objective was to precisely determine the independent variables that could predict the dependent variable. In this linear regression analysis, the independent variables were entered simultaneously into the regression analysis.

\subsection{Assumptions}

Assumptions of multiple linear regression analysis consist of multicollinearity, linearity, normality of the errors, and homoscedasticity (Steven, 1996). Testing for multicollinearity is important, because the impact of multicollinearity decreases the interpretation of a specific coefficient although the overall predictive power of the model might be good. A high multicollinearity means that an independent variable is highly predicted by other independent variables (Hair, et al., 2006). Two criteria, including tolerance value and variance inflation factor (VIF), were applied to explore multicollinearity. These two measures show the degree that each independent variable is explained by other independent variables, meaning that an independent variable becomes a dependent variable against the remaining independent variables (Hair, et al., 2006).

The results of collinearity statistics indicated that there is no problem of multicollinearity. Table 1 shows the tolerance and the VIF values relating to each independent variable. As it can be observed, all tolerances and VIF values are significantly greater than 0.1 and smaller than 10 respectively, which met the values of the rule of thumb. 
Normality was evaluated using a histogram and p-p plot of the standardized errors. The histogram and probability plot obtained for the data set are revealed in Figures 2 and 3 . According the histogram and p-p plot, the errors appeared to be normally distributed, and this data set met the normality assumption.

Finally, the standardized residuals versus the standardized predicted are shown in Figure 4. In this scatter plot, the points should be symmetrically distributed around a diagonal line in the former plot or a horizontal line in the latter plot. As Figure 4 shows, the visual analysis proposed that the linearity assumption has also been met.

Table 1: Results of Multicolinearity Diagnostics for the Model Using Co-Linearity Statistics

\begin{tabular}{lccc}
\hline \multicolumn{4}{c}{ Colinearity Statistics } \\
\hline Variable & Tolerance & VIF & Evidence of multicollinearity \\
\hline Previous Experience & .891 & 1.122 & No evidence \\
Education & .908 & 1.101 & No evidence \\
Attitude & .566 & 1.766 & No evidence \\
Subjective norms & .810 & 1.235 & No evidence \\
Behavioural control & .487 & 2.053 & No evidence \\
Age & .884 & 1.131 & No evidence \\
\hline
\end{tabular}

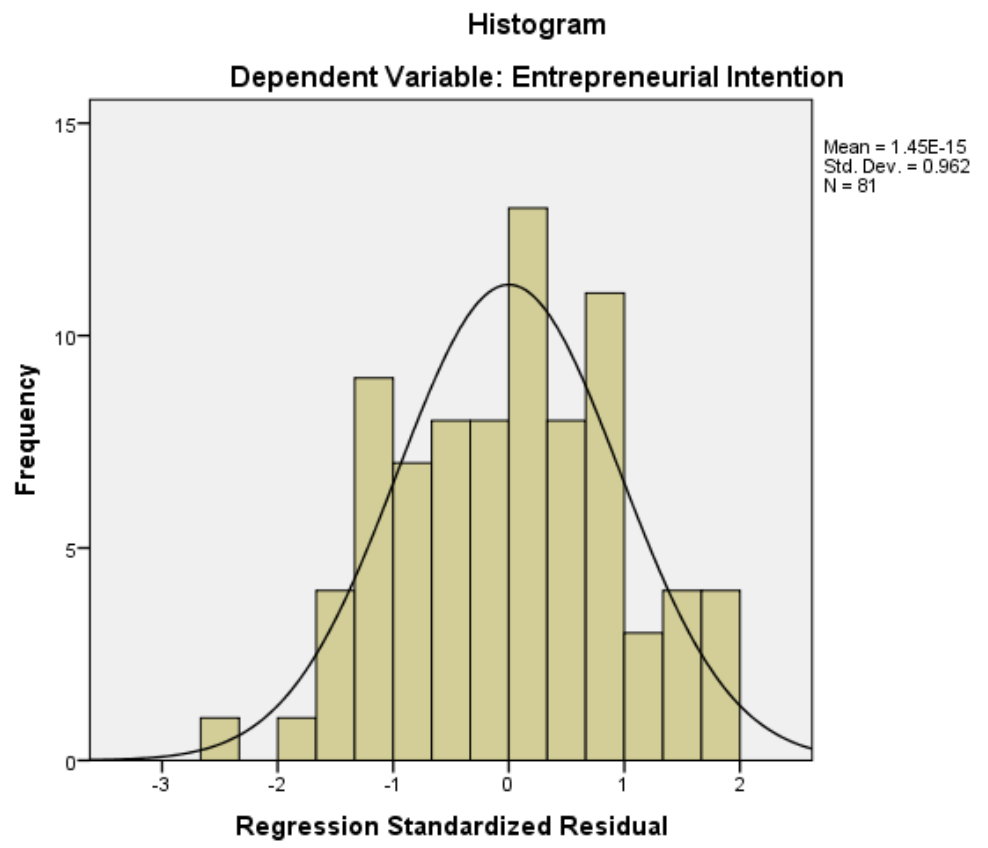

Figure 2: Frequency Distribution of Standardized Errors on the Dependent Variable Which Shows Normality 


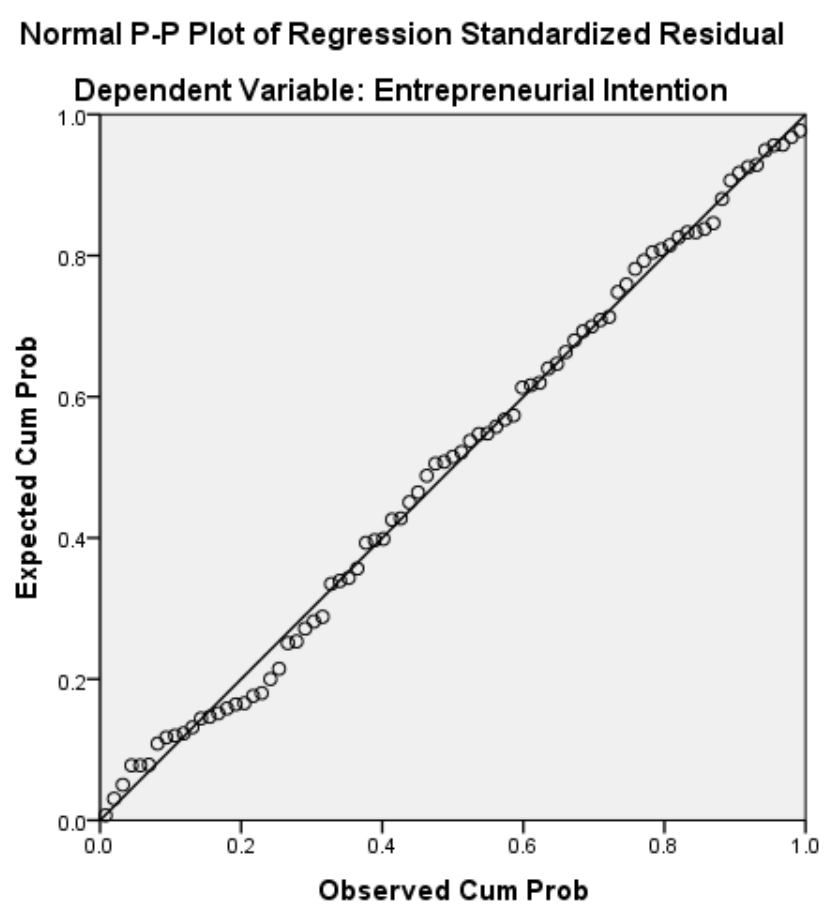

Figure 3: P-P Plot of Standardized Errors on the Dependent Variable Which Reveals Normality

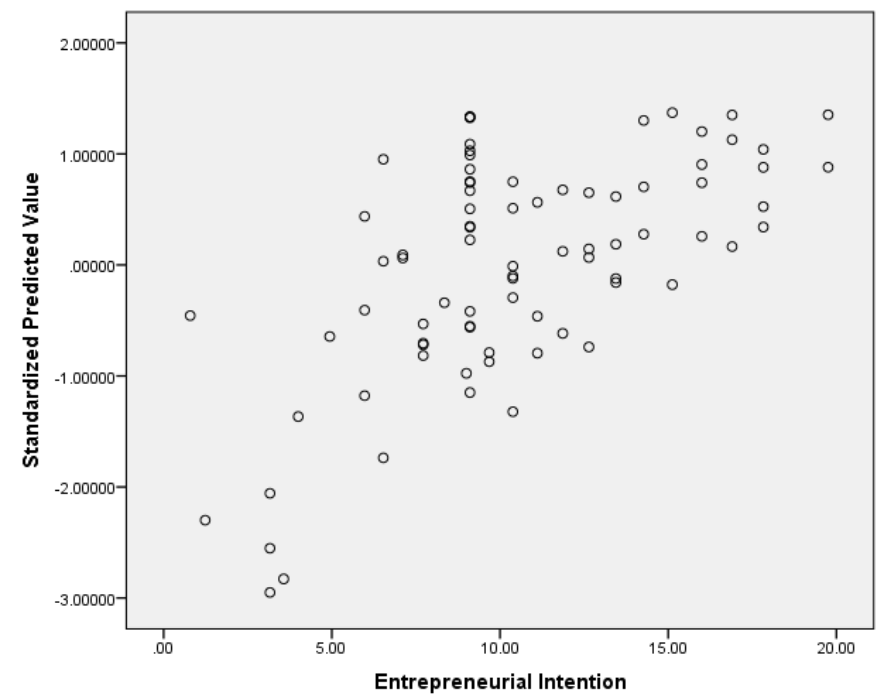

Figure 4: Regression Standardized Predicted Values Plotted against the Regression Standardized Errors for the Dependent Variable Which Reveals Linearity

\subsection{Inferential Statistics}

In this section, some appropriate statistical tests are applied to examine the relationships among the variables based on the research objectives. To construct the independent and dependent variables, the means of items related to each variable in the questionnaire have been calculated. Table 2 presents some descriptive statistics of the variables. As can be seen, Skewness and Kurtosis values for all research variables are less than 1 . We can therefore accept that the distribution of variables does not differ much from normal distribution and being normal theory about those variables is true. 
Table 2: Descriptive Statistics of Research Variables

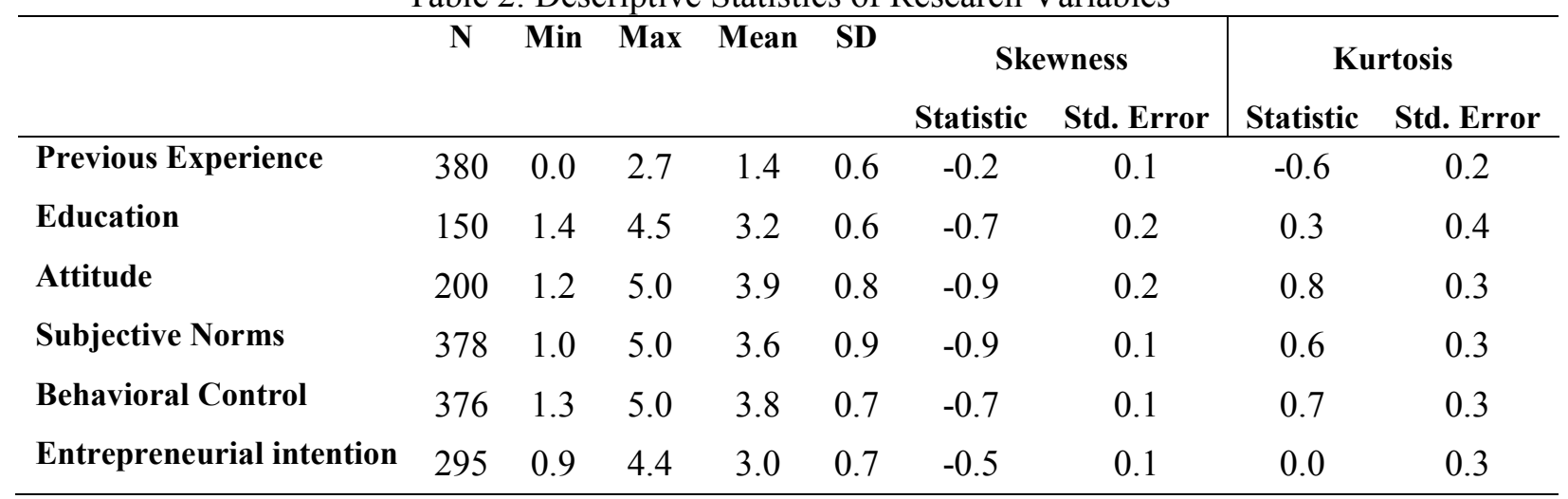

A multiple regression analysis was used to study the relationship among previous experience, education, attitude, subjective norms, perceived behavioral control and age as independent variables and entrepreneurial intention as dependent variable. The main objective was to accurately define the independent variables that help predict the dependent variable. The independent variables were keyed in concurrently into the regression analysis during this linear regression analysis.

The results of multiple regression analysis with the independent variables which entered simultaneously indicated that the independent variables as a group significantly contributed to the prediction of entrepreneurial intention. The independent variables were entered into the regression analysis as a group. Based on the multiple regression results, the independent variables predicted $39 \%$ of the entrepreneurial intention $(\mathrm{F}=7,707, \mathrm{p}<0.05)$. Table 3 shows that among all the independent variables, two variables (age and attitude) remained in the model but previous experience, education, subjective norms and perceived behavioral control are dropped. The $\mathrm{R}$ square obtained on this sample is quite significant. Based on Cohen's (1977) guidelines, an R square on 0.26 is considered to be large. In the current sample, the large R square suggests that the effects are not simply due to a large sample. The same effects would likely have been found even with a much smaller sample size. This indicates that the current study has much practical significance.

Also Table 4 presents more details about this model. As Table 4 demonstrates, among all six independent variables, two variables namely attitude and age have significant effect on the entrepreneurial intention $(\mathrm{B}=2.68$, Beta $=0.45, \mathrm{t}=3.69, \mathrm{p}<0.01)$ and $(\mathrm{B}=-0.16$, Beta $=-0.215, \mathrm{t}=$ $-2.22, \mathrm{p}<0.05)$, respectively.

Table 3: Summarized Information of ANOVA for Regression of Entrepreneurial Intention on Previous Experience, Education, Attitude, Subjective Norms, Behavioral Control, and Age

\begin{tabular}{rlrrrrr}
\hline Model & & $\begin{array}{c}\text { Sum of } \\
\text { Squares }\end{array}$ & df & Mean Square & F & Sig. \\
\hline & Regression & 555.29 & 6 & 92.55 & 7.71 & $.000^{\mathrm{b}}$ \\
1 & Residual & 888.68 & 74 & 12.01 & & \\
& Total & 1443.97 & 80 & & &
\end{tabular}

\footnotetext{
a. Dependent Variable: Entrepreneurial Intention

b. Predictors: (Constant) Age, Education, Previous experience, Subjective, Attitude, Behavioral control
} 
Table 4: Regression Coefficients of Previous Experience, Education, Attitude, Subjective Norms, Behavioral Control, and Age in Relation with Entrepreneurial Intention

\begin{tabular}{lccc|c|c}
\hline \multirow{2}{*}{ Model } & \multicolumn{2}{|l|}{ Unstandardized Coefficients } & Standardized Coefficients & & \\
\cline { 2 - 4 } (Constant) & $\mathrm{B}$ & Std. Error & Beta & $\mathrm{t}$ & Sig. \\
Previous Experience & 1.864 & 4.031 & & .462 & .645 \\
Education & .093 & .776 & .012 & .120 & .905 \\
Attitude & -.686 & .768 & -.086 & -.893 & .375 \\
Subjective Norms & 2.675 & .725 & .447 & 3.692 & .000 \\
Behavioral Control & -.481 & .528 & -.092 & -.910 & .366 \\
Age & 1.567 & .906 & .226 & 1.731 & .088 \\
& -.160 & .072 & -.215 & -2.217 & .030 \\
\hline
\end{tabular}

a. Dependent Variable: Entrepreneurial Intention

\section{CONCLUSION}

The objective of this research was to find out which factors are significant and influential on entrepreneurial intention of postgraduate students in Malaysia. In this study, data were collected from 380 students. The majority of the respondents were between 27-32 years old. According to the results, it can be concluded that, firstly, attitude has direct effect on entrepreneurial intention but age has inverse effect. Secondly, the findings showed that these two variables are more important than others in modeling and predicting the entrepreneurial intention among postgraduate students in Malaysia.

This study has shown the most important factors which influence entrepreneurial intentions among postgraduate students. The results can be helpful for Malaysian government and university policy makers who try to motivate students to become entrepreneurs. It has been suggested that entrepreneurship courses be included as compulsory courses for business programmes in Malaysian universities. Furthermore, the universities are recommended to invite famous entrepreneurs and hold free entrepreneurship workshops for postgraduate students. The implications of the results can assist educators, policy makers, as well as students to understand the importance of the most significant factors including attitude, age and education as the key pre-requisites of entrepreneurial intention and behavior.

\section{References}

[1] Brockhaus, R. H., \& Horwitz, P. (1986). The psychology of the entrepreneur. 1996) Entrepreneurship: critical perspectives on business and management, 2, 260-283.

[2] Brockhaus, R. H., \& Nord, W. R. (1979). An Exploration of Factors Affecting the Entrepreneurial Decision: Personal Characteristic vs. Environmental Conditions. Paper presented at the Academy of Management Proceedings.

[3] Bygrave, W. D. (1993). Theory building in the entrepreneurship paradigm. Journal of Business Venturing, 8(3), 255-280.

[4] Davidsson, P. (1995). Determinants of entrepreneurial intentions.

[5] Gartner, W. (1989) Who is an Entrepreneur? Is the Wrong Question? Entrepreneurship Theory and Practice, 47-68.

[6] Gay, L. R., \& Diehl, P. (1992). Research methods for business and management: Macmillan Coll Div.

[7] Goedhuys, M., \& Sleuwaegen, L. (2000). Entrepreneurship and growth of entrepreneurial firms in Cote d'Ivoire. The Journal of Development Studies, 36(3), 123-145. 
[8] Gupta, V. K., Turban, D. B., Wasti, S. A., \& Sikdar, A. (2009). The role of gender stereotypes in perceptions of entrepreneurs and intentions to become an entrepreneur. Entrepreneurship Theory and Practice, 33(2), 397-417.

[9] Kasomo, D. (2006). Research methods in humanities and education. Egerton: Egerton University.

[10] Kirchhoff, B., \& Greene, P. G. (1995). Response to renewed attacks on the small business job creation hypothesis. Frontiers of Entrepreneurship Research, 1-14.

[11] Kniveton, B. H. (2004). The influences and motivations on which students base their choice of career. Research in Education, 72(1), 47-59.

[12] Kothari, C. (2004). Research methodology: methods and techniques: New Age International.

[13] Krejcie, R. V., \& Morgan, D. W. (1970). Determining sample size for research activities. Educ Psychol Meas.

[14] Krueger, N. F. (1993). The impact of prior entrepreneurial exposure on perceptions of new venture feasibility and desirability. Entrepreneurship Theory and Practice, 18(1), 5-21.

[15] Levesque, M., \& Minniti, M. (2006). The effect of aging on entrepreneurial behavior. Journal of Business Venturing, 21(2), 177-194.

[16] Matthews, C. H., \& Moser, S. B. (1996). A longitudinal investigation of the impact of family background and gender on interest in small firm ownership. Journal of Small Business Management, 34, 29-43.

[17] Naughton, T. (1987). Quality of working life and the self-employed manager. American Journal of Small Business, 12(2), 33-40.

[18] Peterman, N. E., \& Kennedy, J. (2003). Enterprise education: Influencing students' perceptions of entrepreneurship. Entrepreneurship Theory and Practice, 28(2), 129-144.

[19] Reynolds, P. D. (1987). New firms: societal contribution versus survival potential. Journal of Business Venturing, 2(3), 231-246.

[20] Robinson, P. B., Stimpson, D. V., Huefner, J. C., \& Hunt, H. K. (1991). An attitude approach to the prediction of entrepreneurship. Entrepreneurship Theory and Practice, 15(4), 13-31.

[21] Ronstadt, R. (1989). The corridor principle. Journal of Business Venturing, 3(1), 31-40.

[22] Scherer, R. F., Adams, J. S., Carley, S., \& Wiebe, F. A. (1989). Role model performance effects on development of entrepreneurial career preference.

[23] Scott, M. G., \& Twomey, D. F. (1988). The long-term supply of entrepreneurs: students' career aspirations in relation to entrepreneurship. Journal of Small Business Management, 26(4), 5-13.

[24] Shapero, A., \& Sokol, L. (1982). The social dimensions of entrepreneurship. Encyclopedia of entrepreneurship, 72-90.

[25] Singh, G., \& DeNoble, A. (2003). Early retirees as the next generation of entrepreneurs. Entrepreneurship Theory and Practice, 27(3), 207-226.

[26] Vesper, K. H.(1980), New venture strategies: Prentice-Hall, Englewood Cliffs, NJ. 